\title{
ON DEFINING ART AS A LANGUAGE: A COMPARISON OF LANGUAGING AND DRAWING PROCESSES
}

\section{June Eyestone}

I have chosen to write this paper as a means for enhancing my belief that art is a language. My thinking stems from processes in creating language more than interpretation of created language. Specifically, the two processes to be discussed are the kind of thinking that a child uses in developing his or her oral language and the kind of thinking an artist uses in developing a drawing.

In discussing the kind of thinking that a child uses to develop his or her language, a sociopsycholinguistic perspective is taken. According to Halliday (1978), this means "interpreting language within a sociocultural context, in which the culture itself is interpreted in semiotic terms as an information system. .." (p. 2). Semiotic learning is a system of understanding through signs in the environment. Signs are considered to be anything that gives meaning in the environment including words, symbols, gestures, intonation of sounds, etc. Charles Peirce (1931-1958) described three interdependent categories of the process through which signs become meaningful. The category Firstness is about perception or feeling. It is the ability to "see the world freshly without preconceptions" (Nadaner, 1983), the assimilation or inventorytaking or signs. The category Secondness involves a reaction or response to that which is perceived through Firstness. Secondness occurs when those perceptions or feelings from Firstness are in some way connected or related through effort or struggle (Crenshaw, 1985).

An example of the interrelationship between Firstness and Secondness can be seen in Robert Frost's poem The Road Not Taken:

Two roads diverged in a yellow wood, And sorry I could not travel both And be one traveler, long I stood And looked down one as far as I could To where it bent in the undergrowth;

In this first stanza, we can see that there is a dependency of the perception of what is before the traveler - two long, diverging roads, bending in the undergrowth of a yellow wood, and his or her response to it - regret that he or she could not travel both. The element of struggle is evidenced in having to make a choice.

In the next seven lines:

Then took the other, as just as fair, And having perhaps the better claim, Because it was grassy and wanted wear; Though as for that, the passing there Had worn them really about the same, And both that morning equally lay In leaves no step had trodden black. 
We can again see the interrelationship of Firstness and Secondness in the description of the quality of the roads - one worn and one wanting wear, and that that description is influencing the traveler's response. We can also see that the choice has been made as Frost weaves us unwittingly into Peirce's category of Thirdness. This category joins the sign and its response to produce meaning through synthesis, evaluation, application, and judgment. We can see how the traveler has experienced Thirdness and thus derived meaning in the last eight lines of the poem:

Oh, I kept the first for another day!

Yet knowing how way leads on to way, I doubt if I should ever come back.

I shall be telling this with a sigh

Somewhere ages and ages hence:

Two roads diverged in a wood, and I-

I took the one less traveled by,

And that has made all the difference.

Thus, the interconnectedness of the three categories of Peirce's process through which signs become meaningful, illustrated through Frost's poem about making choices, is a triangular relationship, in that once meanings are assimilated, they become signs in the context of a heightened consciousness.

The interpretation of signs in a semiotic environment as described by Peirce parallels Teale's (1978) description of Piaget's theory of cognitive development called constructivist structualism:

(Piaget observed) intellectual growth as a process of assimilating new experiences to the current state of the child's cognitive organization, a process which requires accomodation of existing mental structures and which, in turn, forms part of the mental organization which allows for intake, or assimilation, of additional new experiences. In this manner, the child constructs intellectual principles and constantly reinvents his or her own organization of knowledge. (p. 557)

In oral language development, the child then, has an existing mental structure with which he or she can assimilate and organize semiotic signs from new experiences so that they make sense according to what the child knows. The child takes in new information, makes meaning from it, then hypothesizes new structures and tries them out for clarification and depth in understanding.

Halliday (1978) described semiotic learning of oral language:

It involves the difficult task of focusing attention simultaneously on the actual and potential, interpreting both discourse and the linguistic system that lies behind it in terms of the linguistic system that lies behind it in terms of the infinitely complex network of meaning potential that is what we call the culture. (p. 4-5)

In other words, children learn language through transactions with others in the environment, rather than being taught by someone. They learn from the 
that is, previous drawing experiences in the form of heightened consciousness. The child also sees the world in a fresh way. He or she finds signs that give language meaning and explores new ways to communicate.

For me the heightened consciousness takes the form of a kind of mental structure that leads to a certain ordering and reordering of parts to create a certain whole. I start each drawing with subject matter that interests me structurally so that it will work with my drawing process. This is an intuitive judgment. I am very interested in the most essential qualities of content and form hence I choose to draw bones suspended in space. I start the drawing by internalizing the space with which I have to work, that is the whiteness of the paper, the texture of the paper and the size and shape of the space before me. In suspending the bones, I try to accomplish an infinite space while playing off the finite quality of the edges or border of my paper. I choose a tool with which I can manipulate line in order to create a sense of light and thus existense in a certain space. Very important to that choice is the feeling of touch that I can accomplish with that tool. Presently, I am using a $100 \%$ rag, snowy white paper, about 30" $\times 40 "$ ", and a terra cotta colored pencil. The tools are intrinsically important to the success of the work. I constantly examine other tools that will serve these needs.

As soon as I make a mark on the page, the composition is started. The next marks on the page are a response to the previous marks in relation to the picture frame. They are also a response to my visual stimuli, the bones, in describing their shape and volume in existing natural daylight. I search for the most essential quality of line and no more that will create the world as I see it within the space I have allowed. Thus, drawing for me is composing parts both literally (bones) and abstractly (relating marks to edges to create space), like "focusing attention simultaneously on the actual and potential" as Halliday (1978) stated.

I think that it is important to note that a vital part of the process is the response pattern to the work as it is being developed. Recalling Peirce, a person can perceive a sign as an object and understand its meaning. The sign could be a drawing, in this instance a drawing in process, and the object, the drawing's content. The drawing is built onto what exists and it is that which determines the end - it is not a preconceived composition. It does not come from without, it comes from within much like a child constructs language.

While a child responds to verbal language signs in transactions with others, the artist responds to visual signs in artwork. As an artist, I choose certain tools to convey certain ideas, organized by my existing mental structures, and then invent and reinvent in response to what I know exists. Intuitively, I feel as though I am using processes that were innate to me as a young child. I feel as though through drawing, I am "constantly reinventing my own organization of knowledge" (Teale, 1978). Although I can not revisit my childhood and document my learning processes, there is such a strong feeling of recognition and rightness that exists for me in comparing drawing and languaging processes, in believing that art is a language, that I accept it much like David Wyatt accepts a poem in his essay "Choosing in Frost": 
inside-out rather than from the outside-in. They assimilate meaning through choices they make in a broad spectrum of semantic options.

In his article, "On Art and Social Understanding: Lessons from Alfred Schutz," Nadaner (1983) stated that art is a record of human value or choices in meaning. In discussing Schutz's WE-THEY orientation, Nadaner summarized: "The beholding of a work of art takes place in a time which for Schutz, is nothing other than a derived form of the vivid present shared by the partners in a genuine face-to-face relation such as prevails between speaker and listener..." (p. 18). In other words, the response to art might be considered as involving a dialogue or languaging process through visual signs in a semiotic environment. Hence, art might be considered a form of communication of values as choices.

In the relationship between speaker and listener, the kinds of choices a child makes are dependent on the meaning the child attempts to convey. Rather than being taught how to speak, the child assimilates words, intonations, and gestures that he or she hears and sees into his or her own cognitive structuring and then tries new patterns based on what he or she knows and what he or she has taken in in order to create what Lindfors (1980) refers to as communicative competence. Communicative competence was discussed by Hymes (1974) who stressed the importance of context in establishing communication. Seven language functions described by Halliday (1978) in developing communicative competence are:

1. Instrumental - satisfies materials needs, e.g. "I want"

2. Regulatory - controlling behavior of others, e.g. "Do this"

3. Interactional - getting along with others, e.g. "That's nice"

4. Personal - identifying and expressing oneself, e.g. "I am"

5. Heuristic - exploring the world around and inside oneself, e.g. "What is"

6. Imaginative - creating a world of one's own, e.g. "What if"

7. Informative - communicating new information, e.g. "This is"

Communicative competence is knowing how to interact with others, or being able to speak so that one's intention is clearly understood. Learning language, then, is far more than learning sentence structure and grammar. Learning language or languaging is a kind of layering of invention in order to create meaning, a personal expression of oneself.

Just as learning language is more than learning sentence structure and grammar, so is drawing more than the skill in manipulating drawing tools. Drawing also bears the personal stamp of its maker. Nadaner (1983) stated that:

That effort to see the world freshly, without preconceptions, is what the artist attempts in drawing. The artist knows that this effort at perception does lead to a new knowledge of the world in the form of heightened consciousness of what the artist sees. (p. 16)

Although the artist desires to "see the world freshly," he or she does not start with a vacuum; he or she starts with the knowledge that came from before, 
The figure is the same as for love. Given this aesthetic, anything is a poem if you say it is. No one will object to this formulation - it is unarguable - just as no one will be able to agree as to its particular consequences. We must love a poem, as we love anything, of and for itself: And we take it, like this sentence, like a loved one's love, on faith. (p. 137)

\section{REFERENCES}

Crenshaw, S. Interpretations of kindergarten writing: a semiotic focus. Unpublished doctoral dissertation, University of Missouri, 1985.

Halliday, M. Language as a social semiotic. Baltimore: University Park Press, 1978.

Hymes, D. Foundations of sociolinguistics: An ethnographic approach. Philadelphia: University of Pennsylvania Press, 1974.

Lindfors, J. Children's language and learning. Englewood Cliffs, N J: PrenticeHall, 1980.

Nadaner, D. On art and social understanding: Lessons from Alfred Schutz. Journal of Multi-cultural and Cross-cultural Research in Art Education, 1983, 1 (1), 15-22.

Peirce, C. Collected papers (Volumes 1-5). Cambridge: Harvard University Press, 1931-1958.

Teale, W. Toward a theory of how children learn to read and write naturally. Language Arts, 1982, 59 (6), 555-570.

Wyatt, D. Choosing in Frost. In J. Tharpe (Ed.), Frost Centennial Essays II. Jackson: University of Mississippi, 1976. 